\title{
Absence of the celiac trunk in a rectal cancer patient: case report
}

\author{
Deniz Tihan ${ }^{1,2}$, Serdar Babacan², Tuncer Ergin ${ }^{3}$, Uygar Teomete $^{4}$, Özgür Dandin ${ }^{5}$, Illker Kafa ${ }^{2}$ \\ ${ }^{1}$ Department of General Surgery, Şevket Yllmaz Training and Research Hospital, Bursa, Turkey \\ ${ }^{2}$ Department of Anatomy, School of Medicine, Uludă̆ University, Bursa, Turkey \\ ${ }^{3}$ Department of Radiology, Giilhane Military Medical Academy, School of Medicine, Ankara, Turkey \\ ${ }^{4}$ Department of Radiology, Miller School of Medicine, University of Miami, Miami, Florida, USA \\ ${ }^{5}$ Department of General Surgery, Bursa Military Hospital, Bursa, Turkey
}

\begin{abstract}
Trifurcation of the celiac trunk (CT) was first described by Haller in 1756 and named as 'Tripus Halleri'. It is found as a normal anatomical feature in $85 \%$ of the human population in CT images, and variations are observed for the remaining $15 \%$. The rarest CT variation is the absence of CT which is found in $0.4 \%$ of the population. Although agenesis of CT is often asymptomatic, this variation should be considered while planning surgical interventions in the abdomen. Hereby, we report a case of the absence of the CT together with independent origin of the left gastric, splenic and common hepatic arteries from the ventral wall of the abdominal aorta.
\end{abstract}

Keywords: celiac artery; celiac trunk; variation

Anatomy 2016;10(3):235-238 @2016 Turkish Society of Anatomy and Clinical Anatomy (TSACA)

\section{Introduction}

The celiac trunk (CT; celiac artery) the first visceral branch that originates from the abdominal aorta (AA), is a wide and short artery arising just below the aortic hiatus at the level of T12-L1 ${ }^{[1]}$ Its average length is $1-3 \mathrm{~cm}$ and average diameter $5-8 \mathrm{~mm} .^{[2-5]}$

Trifurcation of the CT was first described by Haller in 1756 and named 'Tripus Halleri'. Since then it is considered as a normal anatomical form. ${ }^{[1,3,6]}$ According to Haller, the CT has three branches: common hepatic artery (CHA) which supplies the liver, left gastric artery (LGA) which supplies the stomach, and the splenic artery (SA) which usually arises as tributary elsewhere in this trunk supplying the spleen. The other divisions of CT rarely occur in the human. ${ }^{[1,-5]}$

Variations of the arteries of the CT and their relationship to surrounding structures are of particular importance from a surgical perspective ${ }^{[3]}$ Currently, frequent use of diagnostic and interventional radiologic modalities allows clinicians to diagnose such vascular variations easily. ${ }^{[7,8]}$ In this case report, we present a rare variation of the CT incidentally diagnosed in a rectal cancer patient.

\section{Case Report}

A forty-seven-year-old female patient was admitted to Şevket Yilmaz Training and Research Hospital, Bursa, Turkey with a minimal acute rectal bleeding. She had no significant medical history but non-insulin-dependent diabetes mellitus and $30.8 \mathrm{~kg} / \mathrm{m}^{2}$ body mass index. Physical examination revealed minimally haematochezia and a markedly elevated CEA level $(162.7 \mathrm{ng} / \mathrm{mL})$ was found on blood tests. Colonoscopy was performed and an ulcerated mass was detected at the proximal part of the rectum. The patient underwent biopsy and colorectal adenocarcinoma was diagnosis with histopathological examination. Computed axial tomography scanning was performed to investigate metastasis, and the absence of the CT was found incidentally: the left gastric, splenic and common hepatic arteries were found to arise independently from the anterior wall of the AA (Figure 1). 
The patient underwent an anterior resection with complete total mesorectal excision. During the exploration, no visceral ischemia was observed due to anomalous pattern of the CT, thus no intervention was performed to the vascular anomaly. The patient was discharged from the hospital on the fourth postoperative day after the anterior resection. After that, she had chemotherapy treatment and no medical or surgical problem due to operation or CT abnormality occurred during her follow-up period. Written informed consent was obtained from the patient for this case report.

\section{Discussion}

During embryological development, right and left dorsal aortas spread out into the segments of embryo by giving dorsal, lateral end ventral branches around the fourth week of development. Each segmental artery of the dor- sal intersegmental arteries of the body wall, lateral splanchnic arteries of the mesonephric ridge and ventral splanchnic arteries of the digestive tube become permanent after forming a single aorta by the fusion of the two dorsal aortas under the fourth thoracal vertebra. Although many of the ventral splanchnic arteries evanesce, three roots (CT, SMA, IMA) in the mesenterium become permanent. ${ }^{[9,10]}$

Anatomical variations of the $\mathrm{CT}$ and its branching pattern are frequently detected during cadaveric dissections and diagnostic radiological imaging. ${ }^{[1,1]}$ Although these variations are usually asymptomatic, they may become important in patients undergoing diagnostic angiography for gastrointestinal bleeding or prior to an operative procedure. They should be considered while planning surgery on the abdominal part of the oesophagus, stomach, duodenum, liver, pancreas, gallbladder and
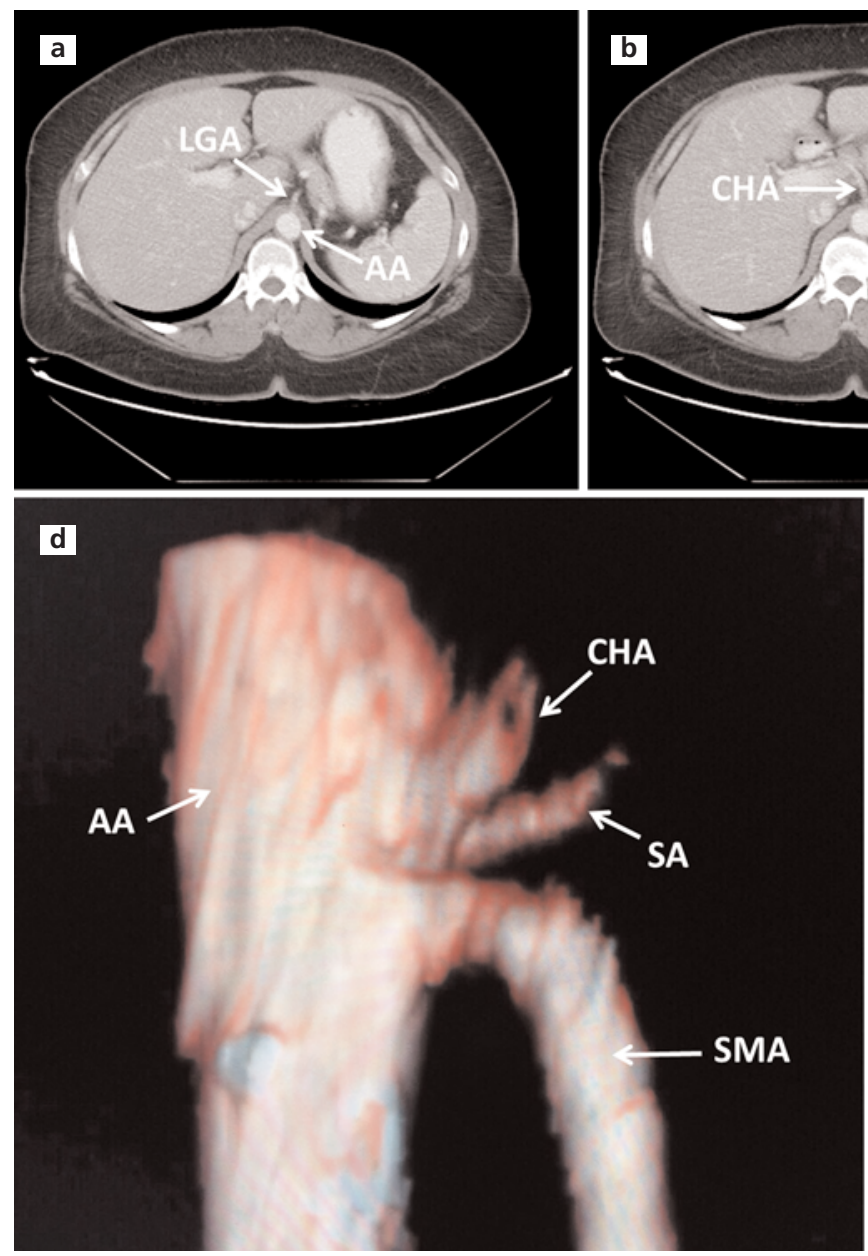
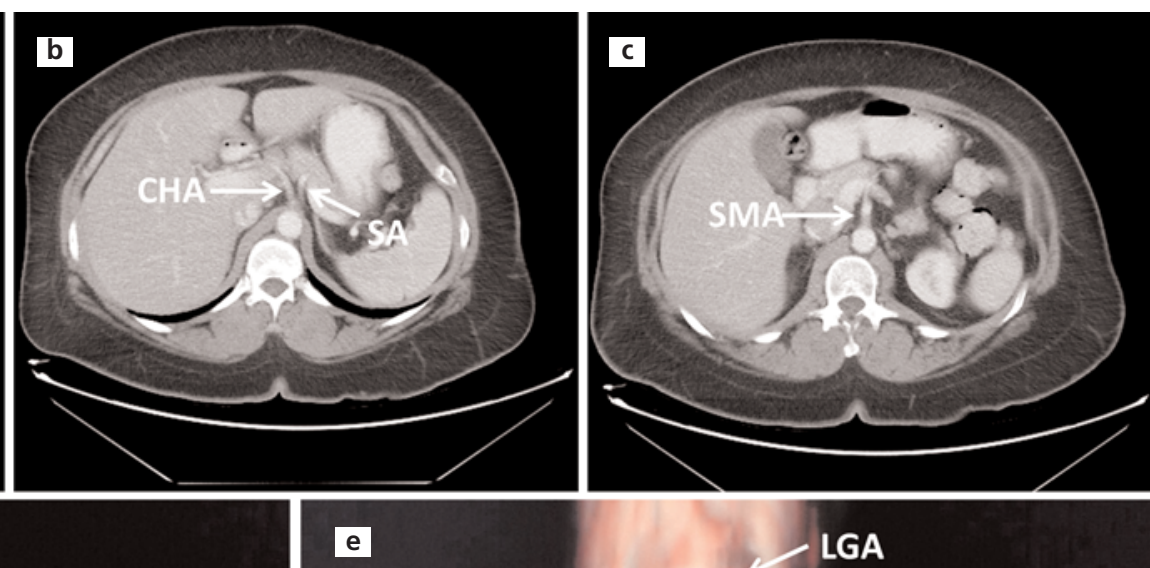

e

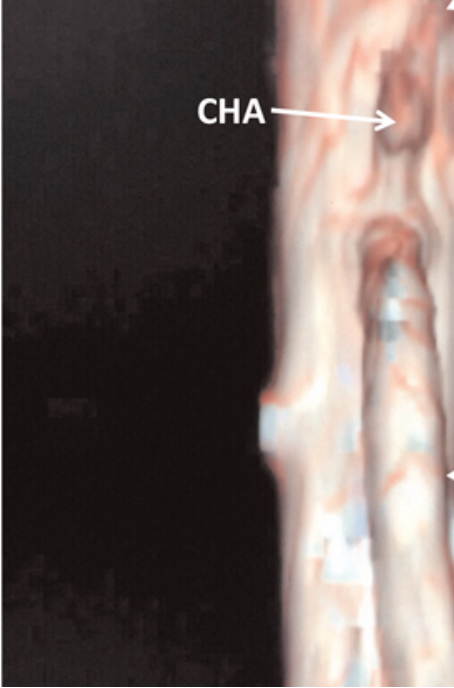

LGA

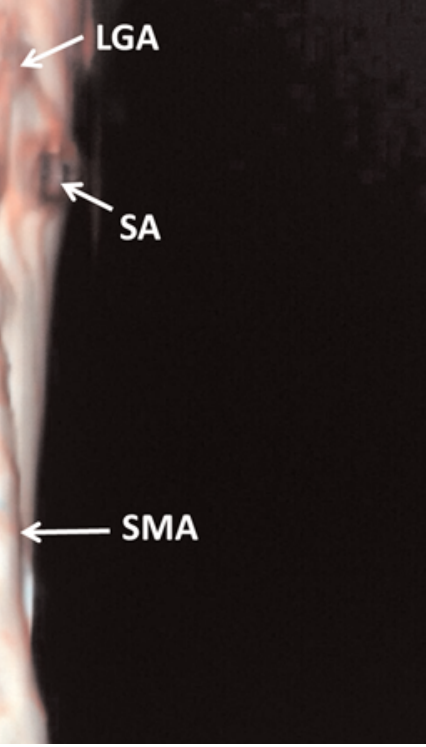

Figure 1. Radiological image of absence of the CT. (a-c) Computed axial tomography images; (d, e) 3D reconstruction of computed axial tomographic angiography. AA: abdominal aorta; CHA: common hepatic artery; LGA: left gastric artery; SA: splenic artery; SMA: superior mesenteric artery. [Color figure can be viewed in the online issue, which is available at www.anatomy.org.tr] 
spleen. ${ }^{[1]]}$ Furthermore, with the advance of interventional techniques for hepatic tumors and the increasing frequency of endovascular procedures and advanced hepatopancreatobiliary surgical procedures such as liver transplantation from the living donors accurate depiction of the CT and its branches has become more important. ${ }^{[5,7,8,11,12]}$

The anatomical variations of CT have been studied in detailed and classified into six types for the first time in 1928 by Adachi. ${ }^{[13]}$ However, not all variations of CT branching have been described in Adachi's classification. Studies have shown that the CT can divide into from two to five or even six different branches in very rare cases; furthermore, all three components branch from the AA independently, so the trunk itself may be absent, described as 'agenesis of celiac trunk'. ${ }^{, 3,14,15]}$

The anatomical variations of CT are due to developmental changes in the ventral splanchnic arteries. ${ }^{[15]}$ Anatomical variations of the CT, superior mesenteric artery (SMA), and inferior mesenteric artery (IMA) have a considerable input in the diversity of the abdominal arterial supply and several branching patterns at this level have been described; yet, the most important one is the congenital absence of the CT, where the LGA, SA, and CHA arise directly from the AA. ${ }^{[12]}$

In 1935, Morita ${ }^{[16]}$ described the first classification system that included an absent CT as a morphological type and the variational pattern of the arteries. He suggested five types with 15 subtypes. According to this classification, the present anomalous case belongs to Type 5 (Typus primitivus), a result of the absence or disappearance of the longitudinal anastomotic channels during the embryonic period, and the four ventral splanchnic arteries grew independently. ${ }^{[17]}$

In the article by Zagyapan et al., ${ }^{[15]}$ digital subtraction angiography data were collected from 152 consecutive donor patients who underwent orthopotic liver transplantation; there was no absence of the CT amongst these cases.

Vanieratos et al. ${ }^{[1]}$ examined 77 adult human cadavers. The absence of the CT was detected in two of the 77 cases $(2.6 \%)$. Ugurel et al. ${ }^{[18]}$ reported that the CT was absent in one in 100 cases (1\%). Prakash et al ${ }^{[11]}$ found anatomical variations of the CT in seven of 50 cadavers. The CT was absent in $2.4 \%$ of the cases.

In a case report and literature review published by Matusz et al., ${ }^{[17]}$ the absence of the CT was reported as varying from $0 \%$ to $1.96 \%$ in cadaveric dissections, from $0 \%$ to $1.11 \%$ in surgical findings and from $0.1 \%$ to $1 \%$ in radiodiagnostic analyses.
Panagouli et al. ${ }^{[19]}$ searched four databases and collected 36 studies with a total number of 12.196 cases the largest series in the literature - in 2013. They reported the classical trifucation in the $89.42 \%(n=10.906)$ of the cases and bifurcation of the CT in $7.4 \%$ of the pooled samples $(\mathrm{n}=903)$. The authors concluded that the rarest variation was the absence of $\mathrm{CT}$ with an incidence of $0.38 \%(n=46)$.

Babu and $\mathrm{Khrab}^{[20]}$ reported a new classification of the CT including most of the variations reported by authors until that time. They compiled the variations of CT under 16 types. 1. Type I: normal trifurcation; 2. Type IIa: hepatosplenic trunk; 3. Type IIb: hepatogastric trunk; 4. Type IIc: gastrosplenic trunk; 5. Type III: no coeliac trunk; 6. Type IVa: coeliacomesenteric trunk; 7. Type IVb: hepatomesentric trunk; 8 . Type IVc: gastro mesenteric trunk; 9. Type IVd: splenomesenteric trunk; 10. Type IVe: hepatosplenomesenteric trunk; 11. Type IVf: gastrosplenomesenteric trunk; 12. Type V: coeliacolic trunk; 14. Type IVa: coeliophrenic trunk (CT+ CIPA - common inferior phrenic artery); 14. Type IVb: coeliophrenic trunk (CT+ RIPA - right inferior phrenic artery); 15 . Type IVc: coeliophrenic trunk (CT+ LIPA left inferior phrenic artery); 16. Type IVd: coeliophrenic trunk (CT+ RIPA + LIPA). Amoung these variations, the case reported in this study was classified under Type III (Figure 2).

The absence of the CT is mostly asymptomatic. The variations, particularly the absence of $\mathrm{CT}$, have no negative effect for the blood supply of the visceral organs. As a matter of fact, independent CHA, LGA and SA may even prevent a large visceral ischemia which may occur in the situation of a massive thromboembolism of the CT.
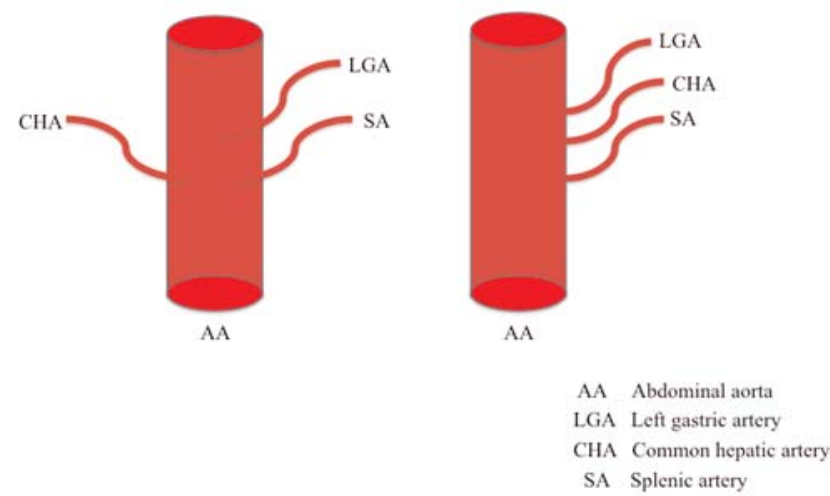

Figure 2. Schematic illustration of the absence of the CT, Type III as described by Babu and Khrab. ${ }^{\left[{ }^{20]}\right.}$ AA: abdominal aorta; CHA: common hepatic artery; LGA: left gastric artery; SA: splenic artery. [Color figure can be viewed in the online issue, which is available at www.anatomy. org.tr] 
The variations in the originating of the CHA, SA and LGA from the AA should be considered by surgeons and interventional radiologists. They should be kept in mind while planning of intraabdominal and/or retroperitoneal surgical operations.

\section{References}

1. Venieratos D, Panagouli E, Lolis E, Tsaraklis A, Skandalakis P. A morphometric study of the celiac trunk and review of the literature. Clin Anat 2013;26:741-50.

2. Malnar D, Klasan GS, Miletic D, Bajek S, Vranic TS, Arbanas J, Bobinac D, Coklo M. Properties of the celiac trunk - anatomical study. Coll Antropol 2010;3:917-21.

3. Nayak SR, Prabhu LV, Krishnamurthy A, Kumar CG, Ramanathan LA, Acharya A, Sinha AP. Additional branches of celiac trunk and its clinical significance. Rom J Morphol Embryol 2008;49:247-9.

4. Songür A, Toktaş M, Alkoç O, Acar T, Uzun I, Baş O, Özen OA. Abdominal aorta and its branches: morphometry - variations in autopsy cases. Eur J Gen Med 2010;7:321-5.

5. Göktay AY, Seçil M, Dicle O. Çölyak trunkus ve hepatik arterlerin normal dallanma varyasyonları: anjiografik bulgular. Tanısal ve Girişimsel Radyoloji 2001;7:226-31.

6. Yilmaz MT, Tezer M, Cicekbasi AE, Aydin A.D, Salbacak A. A case report of coeliacomesenteric trunk. Biomedical Research 2013;24:150-2.

7. Özbülbül NI. CT angiography of the celiac trunk: anatomy, variants and pathologic findings. Diagn Interv Radiol 2011;17:150-7.

8. Gorantia VR, Nayak BS, Potu BK. Variations of the celiac trunk and its branches associated with the shift of vascular hilum (porta hepatis) of the liver. Bratisl Lek Listy 2012;113:120-2.

9. Yalçın B, Kocabıyık N, Yazar F, Ozan H, Özdoğmuş Ö. Variations of the celiac trunk. Gülhane Tip Dergisi 2004;46:163-5.

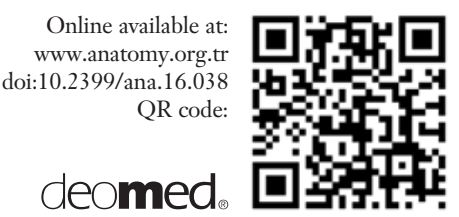

10. Sağıroğlu O, Karakaş S, Ögetürk M, Çetin A, Esen G. Truncus coeliacus ve dalları. Turgut Özal Tip Merkezi Dergisi 1997;4:350-9.

11. Prakash, Rajini T, Mokhasi V, Geethanjali BS, Sivacharan PV, Shashirekha M. Coeliac trunk and its branches: anatomical variations and clinical implications. Singapore Med J 2012;53:329-31.

12. Yi SQ, Terayama H, Naito M, Hirai S, Alimujang S, Yi N, Tanaka $\mathrm{S}$, Itoh $M$. Absence of the celiac trunk: case report and review of the literature. Clin Anat 2008;21:283-6.

13. Adachi B. Das arterien system der Japaner. Vol 2. Kyoto: der Kaiserlich Japanischen Universitaet; 1928. p. 18.

14. Gielecki J, Zurada A, Sonpal N, Jablonska B. The clinical relevance of coeliac trunk variations. Folia Morphol (Warsz) 2005;64:123-9.

15. Zagyapan R, Kürkçüoğlu A, Bayraktar A, Pelin C, Aytekin C. Anatomic variations of the celiac trunk and hepatic arterial system with digital subtraction angiography. Turk J Gastroenterol 2014;25: 104-9.

16. Morita M. Reports and conception of three anomalous cases on the area of the coeliac and the superior mesenteric arteries. Igaku Kenkyu (Acta Med) 1935;9:159-72.

17. Matusz P, Miclaus GD. Ples H, Tubbs RS, Loukas M. Absence of the celiac trunk: case report using MDCT angiography. Surg Radiol Anat 2012;34:959-63.

18. Ugurel MS, Battal B, Bozlar U, Nural MS, Tasar M, Ors F, Saglam M, Karademir I. Anatomical variations of hepatic arterial system, celiac trunk and renal arteries: an analysis with multidetector CT angiography. Br J Radiol 2010;83:661-7.

19. Panagouli E, Venieratos D, Lolis E, Skandalakis P. Variations in the anatomy of the celiac trunk: a systematic review and clinical implications. Ann Anat 2013;195:501-11.

20. Babu D, Khrab P. Coeliac trunk variations: review with proposed new classification. International Journal of Anatomy and Research 2013;1:165-70.

Correspondence to: Serdar Babacan, MD Department of Anatomy, School of Medicine, Uludağ University, Bursa, Turkey Phone: +90 5452264647 e-mail: sbabacan@uludag.edu.tr Conflict of interest statement: No conflicts declared.

This is an open access article distributed under the terms of the Creative Commons Attribution-NonCommercial-NoDerivs 3.0 Unported (CC BY-NCND3.0) Licence (http://creativecommons.org/licenses/by-nc-nd/3.0/) which permits unrestricted noncommercial use, distribution, and reproduction in any medium, provided the original work is properly cited. Please cite this article as: Tihan D, Babacan S, Ergin T, Teomete U, Dandin Ö, Kafa İ. Absence of the celiac trunk in a rectal cancer patient: case report. Anatomy 2016;10(3):235-238. 